Article

\title{
VBS RTK GPS-ASSISTED SELF-CALIBRATION BUNDLE ADJUSTMENT FOR AERIAL TRIANGULATION OF FIXED-WING UAS IMAGES FOR UPDATING TOPOGRAPHIC MAPS
}

\section{Autocalibração de Cameras com uso de VBS RTK para Fotogriangulação de Imagens UAS para atualização de mapas topográficos}

\author{
Shih-Hong Chio \\ Department of Land Economics, National Chengchi University.NO.64, Sec.2, ZhiNan Rd., Wenshan \\ District, Taipei, Taiwan. E-mail: chio0119@gmail.com
}

\begin{abstract}
:
Unmanned Aircraft Systems (UASs) can collect high resolution and high quality images for local mapping. If the highly accurate GPS flying trajectory of a UAS is collected, it can support bundle adjustment aerial triangulation (AT) of UAS images and reduce the demands on ground control points (GCPs). This study installs a Trimble BD970 GNSS OEM on a fixed-wing UAS for capturing highly accurate GPS data by using a Virtual Base Station (VBS) RTK GPS technique for AT. Meanwhile, the GPS antenna-camera offset is resolved by stripwise linear drift parameters introduced in GPS observation equations, while performing bundle adjustment for AT. Additionally, self-calibration bundle adjustment is used in VBS RTK GPS-assisted AT to solve incomplete camera parameters calibrated by a close-range photogrammetric approach. The results show that the AT accuracy of fixed-wing UAS images collected with a $24 \mathrm{~mm}$ focal-length Canon EOS 5D Mark II camera at a flying height of $550 \mathrm{~m}$ above ground level is $0.21 \mathrm{~m}$ in planimetry and $0.22 \mathrm{~m}$ in height using two cross strips with two full GCPs at each corner of the block. The RMSE of check points from stereoscopic viewing can reach $0.27 \mathrm{~m}$ in planimetry and $0.24 \mathrm{~m}$ in height. The test results show that the accuracy of VBS RTK GPS-assisted bundle adjustment with self-calibration for the AT of fixed-wing UAS image can be used for updating local 1/5000 topographic maps in Taiwan.
\end{abstract}

Keywords: VBS RTK GPS, Self-Calibration Bundle Adjustment, Aerial Triangulation, UAS

\section{Resumo:}

Imagens de alta resolução espacial e radiométrica podem ser coletadas por Sistemas de Aeronaves Não Tripuladas (UASs) para fins de mapeamento local. Se a trajetória de um UAS é coletada por antena GPS de alta confiabilidade, os dados obtidos podem ser empregados no processo de fototriangulação e ajudar a reduzir o custo do projeto em apoio de campo (GCPs). Neste trabalho foi instalada uma antena da Trimble BD970 GNSS OEM na asa de um UAS para captar dados GPS usando a técnica GPS RTK da Estação Base Virtual (VBS). O parâmetro de deslocamento linear da origem da antena GPS em relação ao sistema referencial da câmera foi solucionado por fototriangulação. Além disso, uma auto-calibração de câmeras foi usada na fototriangulação assistida por VBS RTK GPS para refinar os parâmetros de orientação interior da camera, determinados com uma calibração prévia a partir de uma abordagem a curta distância. Os resultados mostraram que a partir de uma câmera Canon EOS 5D Mark II com distância focal de $24 \mathrm{~mm}$ e imagens coletadas por um UAS a uma altura de voo em torno de 550 $\mathrm{m}$ a acurácia planimétrica é de $0.21 \mathrm{~m}$ e altimétrica de $0.22 \mathrm{~m}$ usando duas faixas 
fotogramétricas com dois apoios de campo distribuídos nos cantos dos blocos. A RMSE dos pontos de checagem obtidos em estéreoscopia estão em torno de $0.27 \mathrm{~m}$ em planimetria e $0.24 \mathrm{~m}$ em altimetria. Os resultados do teste realizado mostraram que com o emprego do método proposto pode-se atualizar mapas topográficos em Taiwan na escala 1/5000.

Palavra-chave: VBS RTK GPS, Auto-calibração de câmeras; Fototriangulação; UAS.

\section{Introduction}

Unmanned aerial systems (UASs) are commonly used in military applications for reconnaissance, environmental observation, maritime surveillance, mine removal activities, etc. They can be remotely controlled (e.g., flown by a pilot at a ground control station) or can fly autonomously (without pilots on board) by using pre-programmed flight plans (EISENBEISS, 2004). Compared with traditional aerial photogrammetry, UASs offer a novel platform for carrying sensors and flying at required heights, based on mission goals. The majority of commercial photogrammetry and remote sensing applications are conducted with micro UAS and with off-the-shelf cameras or sensors, including: (1) visible-band, near-infrared and multi-spectral cameras; (2) hyperspectral cameras; (3) thermal imaging sensors; (4) laser scanners; and (5) synthetic aperture radar (Colomina and Molina, 2014). Because UASs can fly at low altitude and on cloudy days to collect high resolution and high quality images, UAS technology for low altitude photogrammetric mapping was developed (EISENBEISS, 2009). Although UASs are unsuitable for collecting images of large areas for mapping due to their small image formats, they are suitable for collecting high resolution UAS images for updating local topographic maps. Therefore, orthoimages (Bendea et al., 2007), topographic maps (Li, 2011) and digital elevation models (Haarbrink and Eisenbeiss, 2008) can also be generated for mapping applications.

To ensure accurate mapping applications in the field of traditional aerial photogrammetry, collected aerial images should first be positioned and oriented. There are two approaches for positioning and orientating aerial images: direct georeferencing and indirect georeferencing. The direct approach employs GPP/IMU (Inertial Measurement Unit) instruments, i.e. the POS (Position and Orientation System) system, to determine the exterior orientation parameters of UAS images by post-processing mode. Conversely, if the position and orientation of images is determined by performing aerial triangulation (AT) with ground control points (GCPs) or airborne GPS-assisted controls, it is called the indirect georeferencing approach. Similarly, the concepts can also be applied to accurate mapping applications using UAS images. Although some studies have focused on direct georeferencing of UAS images (BLÁHA et al., 2011; Chiang et al., 2012; Turner et al., 2014), most commercial UASs cannot carry highly accurate inertial measurement units because of their limited payload. Additionally, only single-frequency carrier phase GPS observations are used for kinematic GPS positioning, and GPS positioning results are only better than navigation-grade GPS positioning results. Therefore, they cannot be used as controls for accurate mapping applications. Colomina and Molina (2014) point out that an orientation system (OS), depending on the orientation requirements, usually includes a mapping-grade or geodetic-grade set of sensors. In the former case, the NS (Navigation System) time-Position-Velocity-Attitude (tPVA) solution can hardly be used as aerial control; therefore, neither direct sensor orientation (DiSO), nor integrated sensor orientation (ISO) makes much sense, thus leaving pure aerial triangulation or indirect sensor orientation (InSO) as the only 
viable options. Indirect sensor orientation ( $\mathrm{InSO})$ refers to the indirect georeferencing approach in this paper. COLOMINA and MOLINA (2014) also state at the time this report was written, that the vast majority of UAS imagery for mapping is being processed with the InSO method; i.e. deriving orientation and calibration parameters solely from photogrammetric measurements and GCPs. Thus, while UAS images are used for accurate mapping demands, the indirect georeferencing approach is generally used. The appropriate number of GCPs and their corresponding image coordinates, as well as the tie point coordinates, should be measured. Image point observations and GCP coordinates with corresponding accuracy in combination with accurate camera parameters are then used to determine the exterior orientation parameters of UAS images and the 3-D coordinates of tie points by using the least squares method based on the collinearity equations (Wolf and Dewitt, 2000). This procedure is called bundle adjustment aerial triangulation (AT). However, surveying GCPs is time consuming, labor intensive and expensive. Inaccessible GCP locations, such as those in mountainous areas, increase the cost of surveying control points. Reducing the number of GCPs decreases mapping costs and increases mapping efficiency. In the field of traditional aerial photogrammetry, Friess (1990) applied GPS data on AT to precisely determine the position of aircraft at the camera exposure moment. These GPS data were introduced in a combined block adjustment as eccentric observations (namely, GPS observations) of the positions of the camera perspective center. This substantially reduces the number of necessary terrestrial control points. Control points are then only required for providing geodetic datum.. Thus, using GPS observations as additional observations improves the practicality and economy of AT projects. Additionally, the blocks are effectively controlled by GPS air stations, and in such densely controlled blocks, little error propagation occurs, and the accuracy distribution within the block is highly uniform. Accuracy also depends very little on block size, and is close to the mere intersection accuracy of homologous rays. Therefore, geodetic ground control is no longer required to control photogrammetric block accuracy. This shows that highly accurate GPS observations can be collected and used as air controls for bundle adjustment AT of UAS images, in theory. Some commercial UASs are already equipped with their own GNSS receiver to capture the accurate image locations, such as eBee UAS (https://informedinfrastructure.com/9061/sensefly-announces-ebee-rtk-survey-grade-mapping-dr one/), TopoDrone-100 UAS (http://new.dronemetrex.com/products/topodrone-100/), UAVER Avian UAS (http://www.uaver.com/product-Avian-RTK(PPK)-Avian-RTK.html), UX5 HP UAS (http://uas.trimble.com/ux5-hp), However only eBee UAS uses the VBS RTK technique to capture image locations. Moreover, no related study has been published to discuss the accuracy of UAS image position and orientation, or the possibility of updating local topographic maps. Therefore, this study installs a Trimble BD970 GNSS OEM on a fixed-wing UAS for capturing highly accurate GPS data by using the Virtual Base Station (VBS) RTK GPS technique for AT, and investigates the above problems wherein self-calibration bundle adjustment is used in VBS RTK GPS-assisted AT to solve incomplete camera parameters calibrated by a close-range photogrammetric approach. The results show that the AT accuracy of fixed-wing UAS images collected with a $24 \mathrm{~mm}$ focal-length Canon EOS 5D Mark II camera at a flying height of $550 \mathrm{~m}$ above ground level can not only be used for updating local 1/5000 topographic maps in Taiwan, but are also able to reduce the number of GCPs to decrease mapping costs and increase mapping efficiency.

\section{Methodology}




\subsection{Collections of Virtual Base Station (VBS) RTK GPS observations}

This study installs a Trimble BD970 GNSS OEM (Trimble, 2014) on a fixed-wing UAS to collect L1/L2 carrier phase data in order to capture highly accurate and precise flying trajectories using the VBS RTK GPS technique. Figure 1 shows the used DoDo Pro fixed-wing UAS, Trimble BD970 GNSS OEM, and related devices carried on the UAS, such as an attitude and heading reference system (AHRS).

After the Trimble BD970 GNSS OEM is installed on the UAS, the accurate flying trajectory of the UAS is calculated by applying the post-processing approach to L1/L2 carrier phase data collected on the UAS and related data from the e-GPS service, i.e. VBS RTK GPS service, from the National Land Surveying and Mapping Center (NLSC) in Taiwan.

For typical aerial photogrammetry, because aerial vehicles are fast, the recorded frequency for GPS data cannot be low. According to ACKERMANN (1992), if the velocity is $200 \mathrm{~km} / \mathrm{h}(55 \mathrm{~m} / \mathrm{s})$, the recorded time should be less than $1 \mathrm{~s}$ to make the difference between the interpolation results from GPS recorded data and actual flight data less than $10 \mathrm{~cm}$, qualifying it to be used as air controls. In this study, a fixed-wing UAS flies at a speed of $30 \mathrm{~m} / \mathrm{s}$, approximately half the speed of conventional aerial photogrammetry aircraft. This study set the GPS recording frequency at $1 \mathrm{~Hz}$ to make the difference between the interpolation results from GPS recorded data and actual flight data less than $10 \mathrm{~cm}$.

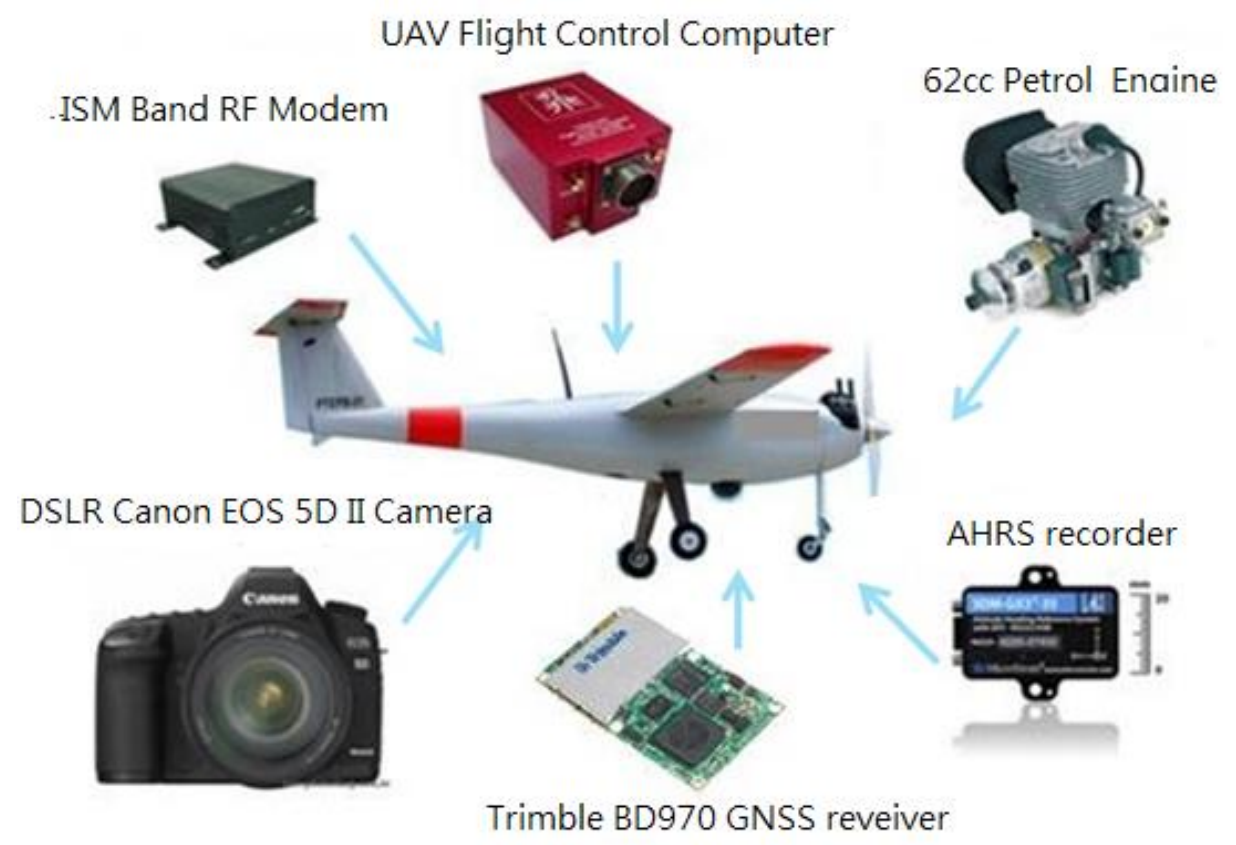

Figure 1: DoDo Pro fixed-wing UAS and related devices installed on the UAS

Additionally, the photogrammetric camera should be equipped with a shutter synchronized electronic signal, providing an accuracy that is higher than $1 \mathrm{~ms}$ if the measuring rate for GPS observations must be $1 \mathrm{~Hz}$, or more because the speed of the aircraft is between $50 \mathrm{~m} / \mathrm{s}$ and 100 $\mathrm{m} / \mathrm{s}$ (Ackermann, 1992). In this study, the UAS exhibits a speed of approximately $30 \mathrm{~m} / \mathrm{s}$. It is also better to have a shutter synchronized electronic signal with an accuracy that is higher than 1 
ms. However, it is difficult to use these types of devices on commercial UASs. That is, it is impossible to keep the recorded times for the GPS data consistent with the camera exposure times. Thus, it is necessary to interpolate from the GPS data, i.e. the accurate GPS trajectory data, based on the exposure time of UAS images to obtain GPS observations that correspond to the exposure time as air controls.

\subsection{VBS RTK GPS-assisted self-calibration bundle adjustment AT}

\subsubsection{Camera Calibration}

Because a non-metric camera is used for acquiring the UAS images in this study, the object distance is set to infinity; therefore, the camera focuses to infinity and the autofocus function is disabled to fix the focus length when the camera is calibrated. However, when a non-metric camera is calibrated by close-range approach using the collected close-range images, the object distance is not infinite, and causes the used calibrated targets on the close-range images to be blurred. This affects the precision of camera calibration and leads to incomplete camera calibration. Even though the camera calibrated by a close-range photogrammetric approach is incomplete, the camera parameters should be calibrated first in order to provide an initial set of better camera parameters for blunder detection while performing VBS RTK GPS-assisted AT. Therefore, the camera parameters are calibrated outdoors by iWitnessPRO software (Photometrix PTY LTD, 2010) in this study, where a special set of 20 coded targets (see Figure 2 ) is designed for an automatic calibration approach. Each coded target consists of 8 black dots on a white background. The used mathematic model for calibration is an Australis model (Fraser, 1997), see Equation 1).

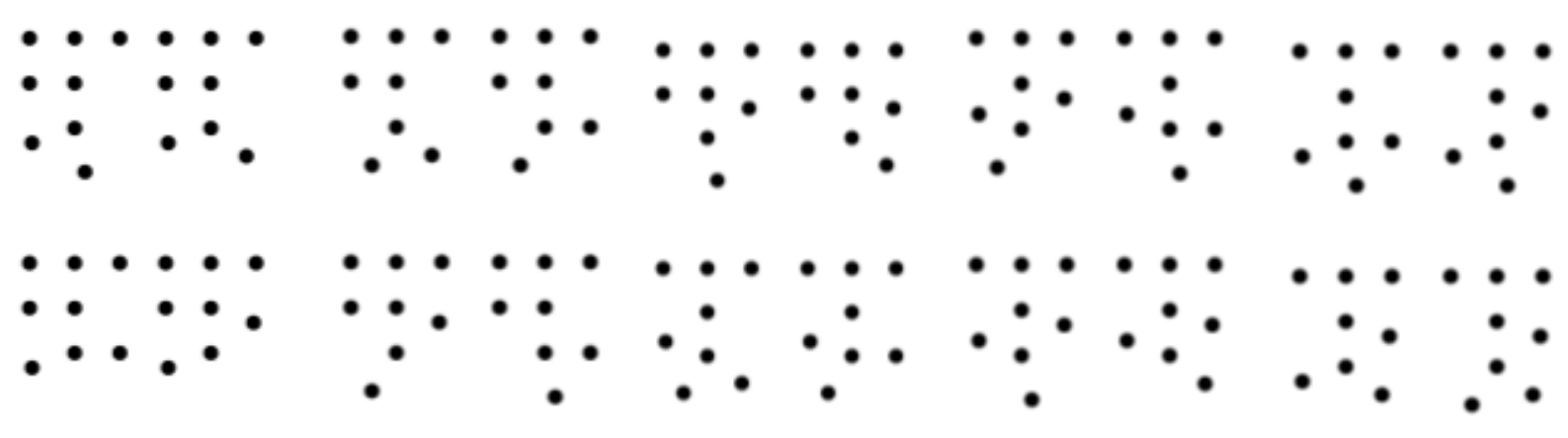

Figure 2: Twenty coded targets using by iWitnessPRO software 


$$
\begin{aligned}
& \Delta x=-\Delta x_{0}-\frac{\bar{x}}{f} \Delta f+\bar{x} r^{2} K_{1}+\bar{x} r^{4} K_{2}+\bar{x} r^{6} K_{3}+P_{1}\left(r^{2}+2 \bar{x}^{2}\right)+2 P_{2} \bar{x} \bar{y}+b_{1} \bar{x}+b_{2} \bar{y} \\
& \Delta y=-\Delta y_{0}-\frac{\bar{y}}{f} \Delta f+\bar{y} r^{2} K_{1}+\bar{y} r^{4} K_{2}+\bar{y} r^{6} K_{3}+2 P_{1} \bar{x} \bar{y}+P_{2}\left(r^{2}+2 \bar{y}^{2}\right)
\end{aligned}
$$

where $\Delta x, \Delta y$ represent the photo coordinate correction for image point

$\Delta x_{0}, \Delta y_{0}$ represent the corrections for principal point coordinates

$x, y$ represent the image point coordinates based on the principal point as the original

$f, \Delta f$ represent the principal distance and its correction

$r$ represents the radial distance of the image point

$K_{1}, K_{2}, K_{3}$ represent the radial distortion parameters

$P_{1}, P_{2}$ represent the decentering distortion parameters

$b_{1}, b_{2}$ represent the linear distortion parameters

In order to carry out automatic calibration, the establishment of an outdoor calibration field abides by certain rules (Photometrix PTY LTD., 2010). A calibration field has been set up at the General Building of Colleges in National Chengchi University. Twenty coded targets are as evenly distributed as possible, as shown in Figure 3. Two boxes are put on the ground at a short distance from the wall to provide the coded targets with different depths. The exposure distance is about $8 \mathrm{~m}$. The nine exposure locations are shown in Figure 4. In Figure 4, low position means that when the photo is taken, the camera is positioned as low as possible; high position means that when the photo is taken, the camera is positioned as high as possible, for example, by standing on a chair. Additionally, the camera is rotated 90 degrees clockwise for each exposure. A total of nine images were taken for the calibration.

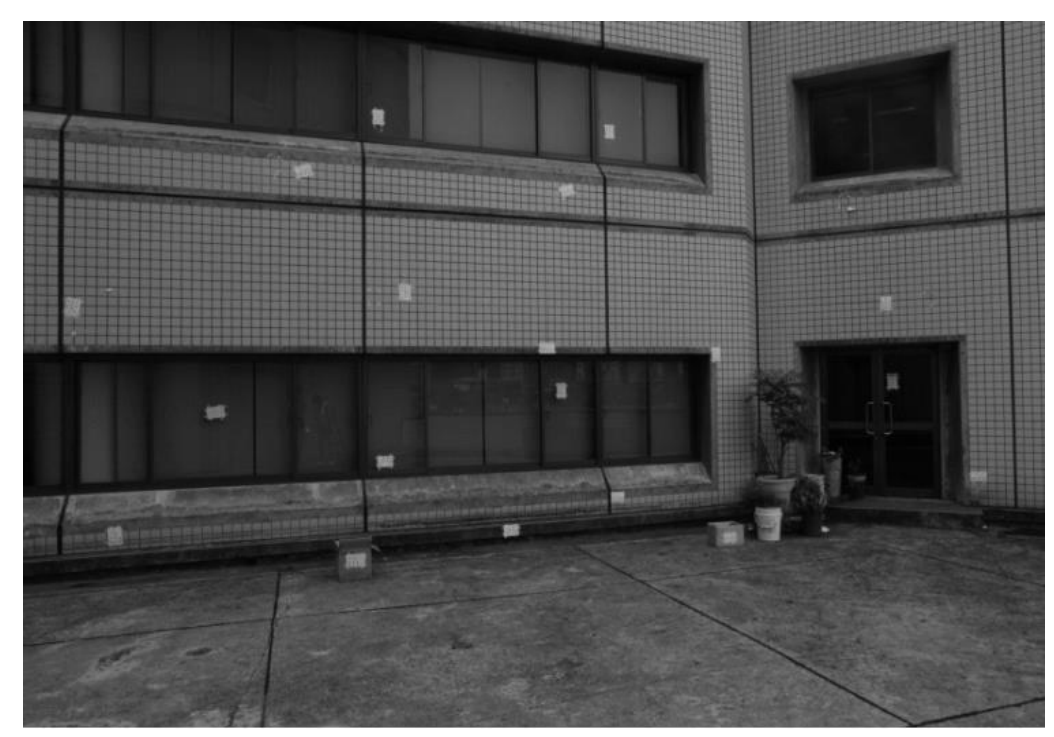

Figure 3: Outdoor calibration field 


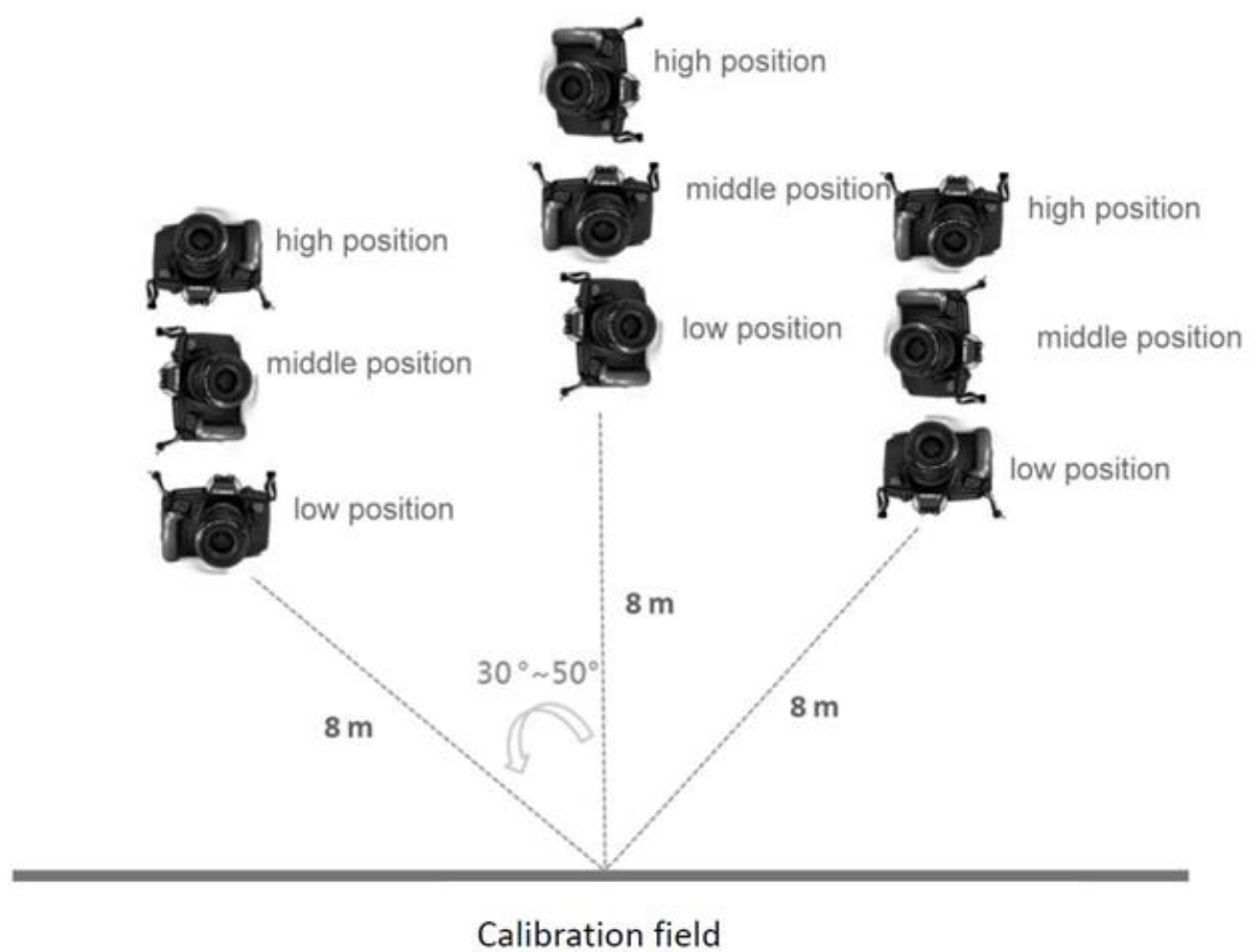

Figure 4: Exposure positions for camera calibration

\subsubsection{Stripwise linear drift parameters for resolving GPS antenna-camera offset}

Any GPS observation interpolated from an accurate trajectory corresponds to the antenna center. The antenna center and the image exposure position cannot occupy the same point in space; this offset is called GPS antenna-camera offset. For accurate mapping applications, the GPS antenna-camera offset should be determined at the centimeter level to reduce GPS observations into the camera perspective center (Blankenberg, 1992; Ebadi, 1997). For traditional aerial vehicles, this offset can be surveyed by terrestrial surveying techniques (Blankenberg, 1992), such as the free station method using fiducial marks as control points (WANG and WANG, 1998). This offset, which is based on the fiducial coordinate system, is then transformed into the offset based on the ground coordinate system (Wang and Wang, 1998). Thus, each exposure position can be determined. However, the CCD (charge coupled device) of the camera is too small and the camera body cannot be opened, making it impossible to conduct a precise survey. In order for the study to be feasible, this problem must be overcome. Hinsken et al. (2002) use the constant parameters of stripwise linear drift parameters in GPS observation equations for the AT of ADS images to decrease the influence caused by GPS antenna-camera offset. Stripwise linear drift parameters contain three constant parameters and three time-dependent parameters per strip. Therefore, this study aims to resolve GPS antenna-camera offset problems by including stripwise linear drift parameters in GPS observation equations, while performing GPS-assisted bundle adjustment AT of UAS images. Stripwise linear drift parameters were also used to 
eliminate time shifts and interpolation errors, as well as to solve problems caused by the inaccurate determination of cycle ambiguity due to cycle slips during the kinematic positioning process, in addition to various geodetic data that appear to be systematic (Blankenberg, 1992; Ackermann, 1994). In this study, the six linear unknown parameters per strip (three offsets and three drifts) are added to the GPS observation equations without loss of lock during the data recording of the GPS antenna center, (see Equation 2 (Hinsken et al., 2002)), while performing GPS-assisted bundle adjustment AT; the six stripwise linear drift parameters are estimated.

$$
\left[\begin{array}{c}
X_{i}^{G P S} \\
Y_{i}^{G P S} \\
Z_{i}^{G P S}
\end{array}\right]+\left[\begin{array}{c}
V_{X}^{G P S} \\
V_{Y}^{G P S} \\
V_{Z}^{G P S}
\end{array}\right]=\left[\begin{array}{c}
X_{i}^{P C} \\
Y_{i}^{P C} \\
Z_{i}^{P C}
\end{array}\right]+\left(\left[\begin{array}{l}
a_{X} \\
a_{Y} \\
a_{z}
\end{array}\right]+\left[\begin{array}{c}
b_{X} \\
b_{Y} \\
b_{z}
\end{array}\right] \times\left(t-t_{0}\right)\right)
$$

where

$X_{i}^{G P S}, Y_{i}^{G P S}, Z_{i}^{G P S}$ represent GPS observations corresponding to image $i$

$V_{X i}^{G P S}, V_{Y i}^{G P S}, V_{Z i}^{G P S}$ represent residuals for $X_{i}^{G P S}, Y_{i}^{G P S}, Z_{i}^{G P S}$ observations

$X_{i}^{P C}, Y_{i}^{P C}, Z_{i}^{P C}$ represent coordinates of the camera perspective center of image $i$

$a_{X}, a_{Y}, a_{Z}$ are three linear drift constant parameters of a strip in object space

$b_{X}, b_{Y}, b_{Z}$ are three time-dependent linear drift parameters of a strip in object space

$\left(t-t_{0}\right)$ represents the time difference between exposure time $t$ of image $i$ and strip beginning

$t_{0}$

\subsubsection{Theory for VBS RTK GPS-assisted self-calibration bundle adjustment AT}

The principle of VBS RTK GPS-assisted self-calibration bundle adjustment AT of UAS images is basically an extension of the bundle adjustment model. This means that the basic collinearity equation is augmented by the additional terms $\Delta x$ and $\Delta y$. The $\Delta x$ and $\Delta y$ terms consist of various additional parameters based on different models. This study used Leica Photogrammetry Suite Orientation Management (LPS ORIMA) (Erdas INC., 2008) photogrammetric software to perform VBS RTK GPS-assisted self-calibration bundle adjustment AT, which adapts the Brown physical model (Brown, 1976). Equation 3 shows the Brown mathematical model originally developed for frame camera calibration. 


$$
\begin{aligned}
\Delta x=x_{0} & +x\left[a_{1}\left(r^{2}-r_{0}^{2}\right)+a_{2}\left(r^{4}-r_{0}^{4}\right)+a_{3}\left(r^{6}-r_{0}^{6}\right)\right]+b_{1} x+b_{2} y \\
& +\frac{x}{c}\left[c_{1}\left(x^{2}-y^{2}\right)+c_{2} x^{2} y^{2}+c_{3}\left(x^{4}-y^{4}\right)\right]+d_{1} x y+d_{2} y^{2}+d_{3} x^{2} y+d_{4} x y^{2}+d_{5} x^{2} y^{2} \\
\Delta y= & y_{0}+y\left[a_{1}\left(r^{2}-r_{0}^{2}\right)+a_{2}\left(r^{4}-r_{0}^{4}\right)+a_{3}\left(r^{6}-r_{0}^{6}\right)\right] \\
& +\frac{y}{r}\left[c_{1}\left(x^{2}-y^{2}\right)+c_{2} x^{2} y^{2}+c_{3}\left(x^{4}-y^{4}\right)\right]+d_{6} x y+d_{7} x^{2}+d_{8} x^{2} y+d_{9} x y^{2}+d_{10} x^{2} y^{2}
\end{aligned}
$$

where

$\Delta x, \Delta y$ represent the corrections of image point coordinate observations

$x_{0}, y_{0}$ represent the principal point coordinates

$c$ represents the calibrated principal distance

$r, r_{0}$ represent the radial distance of the measurement point from the image center and

principal point, respectively.

$a_{1}, a_{2}, a_{3}$ represent the radial lens distortion polynomial coefficients

$b_{1}, b_{2}$ represent the affinity and non-orthogonality of the image system

$c_{1}, c_{2}, c_{3}$ represent the non-flatness of the image plane

$d_{1}, \ldots \ldots, d_{10}$ represent regular and irregular film deformations

Because the main lens distortion results from radial distortion (Clarke et al., 1998), only the radial lens distortion parameters $\left(a_{1}, a_{2}, a_{3}\right)$ of the Brown additional parameters are used when LPS ORIMA photogrammetric software is used to perform VBS RTK GPS-assisted self-calibration bundle adjustment AT of UAS images. Therefore, the camera parameters used for self-calibration include the principal distance $(c)$, principal point coordinates $\left(x_{0}, y_{0}\right)$ and radial lens distortion $\left(a_{1}, a_{2}, a_{3}\right)$.

While performing VBS RTK GPS-assisted self-calibration bundle adjustment AT of UAS images, automatic and manual tie point measurement and blunder detection are performed using LPS ORIMA photogrammetric software. Two image point coordinate observation equations based on the augmented collinearity equations are formed for each (photogrammetric) ray. Three GPS observation equations for each image are obtained using Equation (2). Unknowns are all exterior orientation parameters of UAS images, the six linear drift parameters for each strip, the self-calibration camera parameters and the tie point ground coordinates. After the solution is determined by the least squares principle of indirect observation adjustments, the accuracy of VBS RTK GPS-assisted self-calibration bundle adjustment AT for UAS images is verified by calculating the root mean square error (RMSE) of the check points. Subsequently, the results of stereoscopic viewing will be checked by the statistics of ground horizontal and vertical check points. 


\subsubsection{GCP configuration}

Intuitively, in GPS-assisted AT, the highly accurate GPS observations are regarded as control points, similar to when GCPs rise into the air. In principle, GPS-assisted AT does not require any GCPs. However, the WGS84 coordinate system used for GPS positioning results, and national reference systems, such as TWD97 and TWVD2001 in Taiwan, are generally used as mapping coordinate systems. It is necessary to transform the WGS84 coordinates into the mapping coordinate system. Therefore, at least 2 horizontal GCPs and 3 vertical GCPs are necessary to transform the data. The unknown stripwise linear drift parameters mentioned in the previous section introduce the problem of singularities. The six parameters per strip destabilize the block geometry and may negatively affect the recovery of all unknowns in the adjustment (e.g., normal matrix singularity). Two approaches were used to avoid singularities (Ackermann, 1992): adding two chains of vertical control points or flying two cross strips. Ackermann (1992) states that in case of standard overlap (parallel strips with $20 \%$ side overlap) drift parameters per strip are solved if two chains of vertical control points, running across the block at both front ends are given, in addition to the standard $4 \mathrm{XYZ}$ control points. It is sufficient to run 2 cross-strips across a standard block (20\% side overlap) at either end, the cross-strips replacing the 2 chains of vertical control points. In that case the adjustment can be based on 4 XYZ ground control points alone, although it is suggested to add one vertical control point at each corner of the block. This study introduces linear drift parameters on each strip to overcome the problem of GPS antenna-camera offset and aims to perform self-calibration AT to compensate for the problem of incomplete camera calibration by the close-range calibration method. This introduces more unknowns and determines whether or not the GCP configuration proposed by Ackermann (1992) is suitable. Currently, collecting 3-D GCP control information by GPS techniques, e.g., VBS, RTK GPS, is fast and easy. The heights determined by GPS techniques can be corrected to orthometric heights by transformation, based on enough points with known orthometric heights. Therefore, vertical control points in the abovementioned GCP configuration proposed by Ackermann (1992) are replaced as full control points. Thus, two GCP configurations are formed: (1) two chains of full control points and (2) two cross strips with 2 full GCPs at each corner of the rectangular block, referred to as two cross strips with 8 full GCPs in the latter text.

\section{Experiments and Discussion}

\subsection{Camera calibration results}

The non-metric camera used is a Canon EOS 5D Mark II digital camera with a $24 \mathrm{~mm}$ focal length; the pixel size is $6.4 \mu \mathrm{m}$ and the image size is 5,616 pixels $\times 3,744$ pixels. According to the approach described in subsection 2.2.1, the images for camera calibration are shown in Figure 5, and the calibration results are shown in Table 1. This result will provide an initial one set of better camera parameters for the following test to perform VBS RTK GPS-assisted AT. 

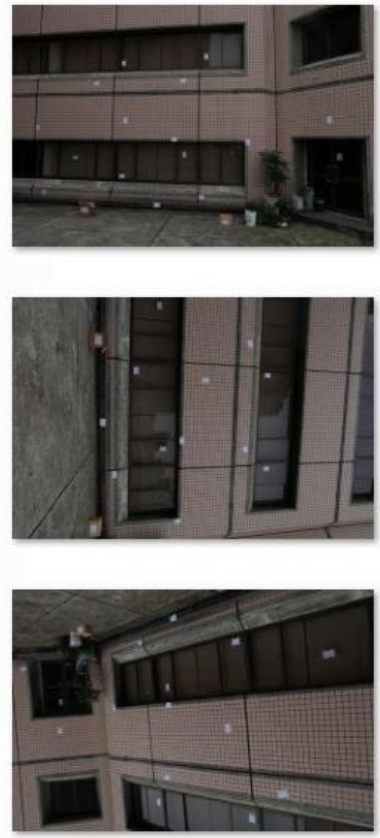
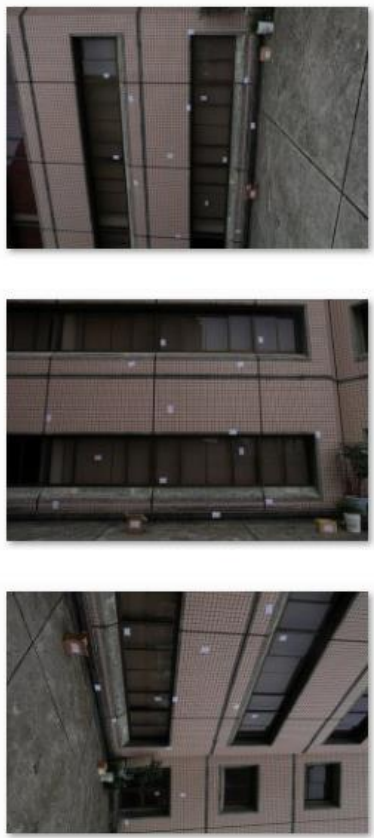
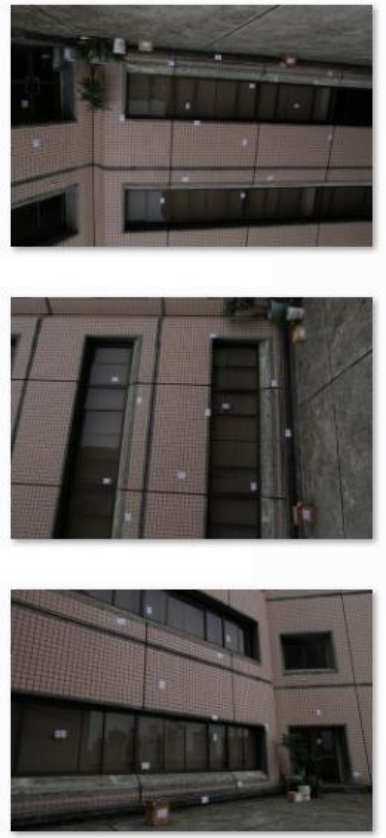

Figure 5: The nine images for camera calibration

Table 1: Calibrated camera parameters

\begin{tabular}{l|c|c}
\hline \multicolumn{2}{c|}{ Camera parameters } & Values \\
\hline \multicolumn{2}{c|}{ Calibrated principal distance $(\mathrm{mm})$} & 24.5980 \\
\hline \multicolumn{2}{c}{ Principal point offsets $(\mathrm{x} 0(\mathrm{~mm}), \mathrm{y} 0(\mathrm{~mm}))$} & $(0.1220,0.1740)$ \\
\hline Radial distortion & $\mathrm{K}_{1}\left(\mathrm{~mm}^{-2}\right)$ & $1.2676000 \mathrm{e}-004$ \\
\hline & $\mathrm{K}_{2}\left(\mathrm{~mm}^{-4}\right)$ & $-3.4274000 \mathrm{e}-007$ \\
\cline { 2 - 3 } & $\mathrm{K}_{3}\left(\mathrm{~mm}^{-1}\right)$ & $3.0652000 \mathrm{e}-010$ \\
\hline Decentering distortion & $\mathrm{P}_{1}\left(\mathrm{~mm}^{-1}\right)$ & $5.7896 \mathrm{e}-006$ \\
\hline \multirow{2}{*}{ Affinity parameter in $\mathrm{x}, \mathrm{y}$ axis scale } & $\mathrm{P}_{2}\left(\mathrm{~mm}^{-2}\right)$ & $9.7399 \mathrm{e}-006$ \\
\hline Affinity parameter in $\mathrm{x}, \mathrm{y}$ axis non-orthogonality & $\mathrm{B}_{1}$ & $-3.016 \mathrm{e}-004$ \\
\hline
\end{tabular}

\subsection{Test of VBS RTK GPS-assisted Self-Calibration AT}

The test was conducted on approximately 300 ha in Jian Township, Hualien County, Taiwan, as 
shown in Figure 6. The test UAS images were captured at a flying height of approximately 550 $\mathrm{m}$ above ground level by a Canon EOS 5D Mark II digital camera with a $24 \mathrm{~mm}$ focal length The shutter speed setting is $1 / 2000 \mathrm{~s}$ and the $f$-stop is 3.2. Meanwhile the ISO setting is automatic. The imaging ground sampling distance is approximately $15 \mathrm{~cm} /$ pixel. In total, 266 UAS images in 9 strips, including 2 cross strips, were collected with an $80 \%$ image end lap and a $45 \%$ image side lap. The exposure time of each UAS image was also recorded based on GPS time. As discussed previously, the accurate flying trajectory for $1 \mathrm{~Hz}$ was determined by applying post-processing. After the accurate flying trajectory of the UAS was determined, the GPS observations corresponding to all the exposure stations of UAS images were interpolated using their corresponding image exposure GPS time to provide highly accurate air controls.

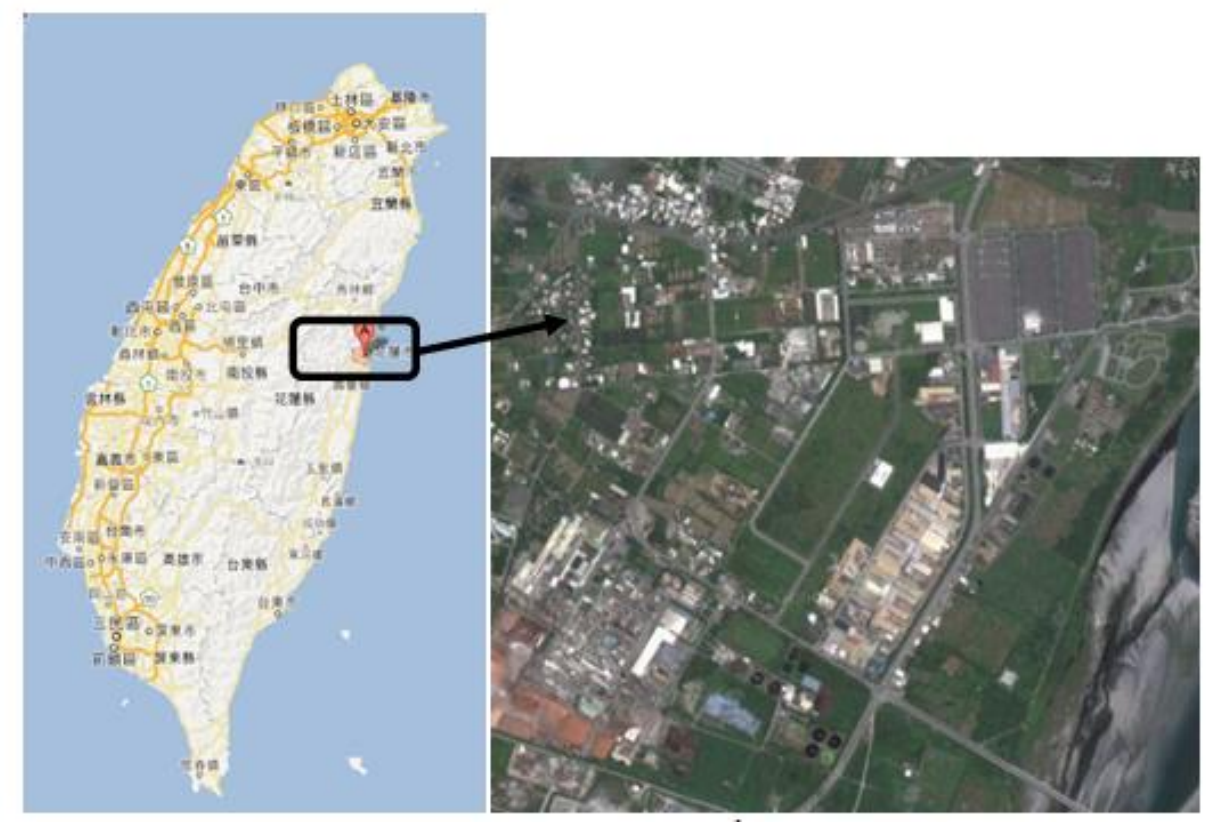

Figure 6: Test Site

The 3-D GCP coordinates and check points were surveyed using the VBS RTK GPS technique, i.e. e-GPS service in Taiwan. The surveyed ellipsoid height was converted to the orthometric height in TWVD2001 based on the five points with known orthometric height surrounding the test site using a Classical 3D Transformation, i.e. 3D-Helmert transformation. The GCP configuration in the test is shown in Figure 7. All GCPs are located on the strip overlap. Because the strip overlap in the lower right corner is on a river (see Figure 6), two GCP locations on this corner were set toward the left. The distribution of the 6 check points is shown as black dots in Figure 7. LPS ORIMA photogrammetric software was used for GPS-assisted AT for the test. All tie points were automatically extracted; blunder detection and necessary manual measurement of tie points were conducted using LPS ORIMA photogrammetric software. While performing GPS-assisted AT, the weight of image point observations was set according to a measurement precision of $6.4 \mu \mathrm{m}$. The weights of GCPs and GPS observations were set according to their corresponding accuracies $(0.05 \mathrm{~m}, 0.05 \mathrm{~m}$ and $0.1 \mathrm{~m})$. 


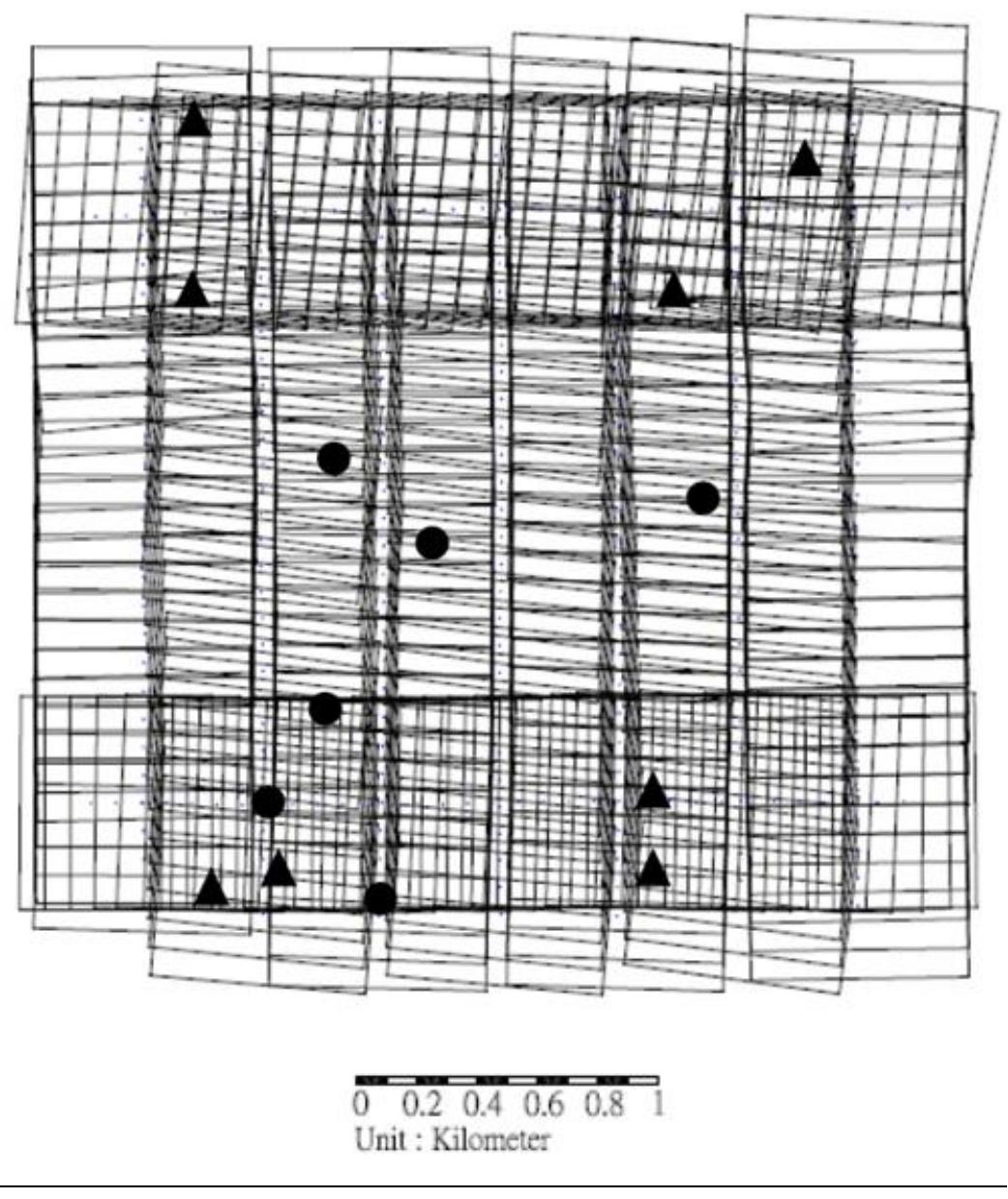

Figure 7: Distribution of 8 full GCPs (triangles) and 6 check points (black dots) for GPS-assisted AT

Because the model of camera parameters used by LPS ORIMA photogrammetric software is the Brown model (Equation 3), this model is different from the Australis model (Equation 1) adopted by close-range calibration approach in subsections 2.2.1 and 3.1. However, when performing self-calibration bundle adjustment, a set of initial camera parameters is necessary for easy blunder detection. In addition, the main lens distortion results from radial distortion (Clarke et al., 1998), and only the radial lens distortion parameters $\left(a_{1}, a_{2}, a_{3}\right)$ of the Brown model are used to perform VBS RTK GPS-assisted self-calibration bundle adjustment AT of UAS images. Therefore, the camera parameters used for self-calibration include the principal distance $(c)$, principal point coordinates $\left(x_{0}, y_{0}\right)$, and radial lens distortion $\left(a_{1}, a_{2}, a_{3}\right)$.

After AT, approximately 6000 ground tie points remained. Firstly, the RMSE of six ground check points from tests of six different types of AT are presented in Table 2 to discuss if the self-calibration bundle adjustment or the linear drift parameters included in GPS measurements improve the accuracies of the AT. These results include the RMSE of six check points using: (1) general bundle adjustment AT using 28 GCPs; (2) general self-calibration bundle adjustment AT using 28 GCPs; (3) GPS-assisted general bundle adjustment AT using 8 GCPs; (4) GPS-assisted self-calibration bundle adjustment AT using 8 GCP; (5) GPS-assisted general bundle adjustment AT without stripwise linear drift parameters using 8 full GCPs; (6) GPS-assisted self-calibration bundle adjustment AT without stripwise linear drift parameters using 8 full GCPs. Figure 8 illustrates the distribution of $28 \mathrm{GCPs}$ of general bundle adjustment AT and general 
self-calibration bundle adjustment AT.

Table 2: Accuracy of six different types of bundle adjustment AT

\begin{tabular}{l|c|c|c|c}
\hline \multirow{2}{*}{ Type of AT } & \multicolumn{3}{c|}{ RMSE of 6 check points (unit: meter) } \\
\cline { 2 - 5 } & $\mathrm{E}$ & $\mathrm{N}$ & $\mathrm{E}-\mathrm{N}$ & $\mathrm{H}$ \\
\hline $\begin{array}{l}\text { (1) General bundle adjustment AT using 28 GCPs } \\
\text { (2) General self-calibration bundle adjustment AT using 28 }\end{array}$ & 0.28 & 0.28 & 0.39 & 0.33 \\
\hline $\begin{array}{l}\text { GCPs } \\
\text { (3) GPS-assisted general bundle adjustment AT using 8 full } \\
\text { GCPs }\end{array}$ & 0.08 & 0.22 & 0.24 & 0.35 \\
\hline $\begin{array}{l}\text { (4) GPS-assisted self-calibration bundle adjustment AT } \\
\text { using 8 full GCPs }\end{array}$ & 0.13 & 0.17 & 0.21 & 0.22 \\
\hline $\begin{array}{l}\text { (5) GPS-assisted general bundle adjustment AT without } \\
\text { stripwise linear drift parameters using 8 full GCPs }\end{array}$ & 0.24 & 0.29 & 0.38 & 21.37 \\
\hline $\begin{array}{l}\text { (6) GPS-assisted self-calibration bundle adjustment AT } \\
\text { without stripwise linear drift parameters using 8 full GCPs }\end{array}$ & 0.51 & 0.29 & 0.58 & 4.09 \\
\hline
\end{tabular}

From Table 2, it is clear that the planimetric accuracy of general bundle adjustment AT using 28 GCPs, i.e. $0.39 \mathrm{~m}$, is improved by the self-calibration approach, and becomes $0.17 \mathrm{~m}$, but there is only a $3 \mathrm{~cm}$ difference in vertical accuracy. The test result shows that self-calibration is necessary.

Additionally, the RMSE of a VBS RTK GPS-assisted general bundle adjustment are $0.24 \mathrm{~m}$ and 0.35 min E-N and $\mathrm{H}$ coordinate components, respectively. The planimetric E-N accuracy is worse than that of general self-calibration bundle adjustment AT using 28 GCPs. The vertical $\mathrm{H}$ accuracy is almost the same as that of general self-calibration bundle adjustment AT using 28 GCPs. However, after GPS-assisted self-calibration bundle adjustment AT was performed, the RMSEs in E-N and $\mathrm{H}$ coordinate components are improved to $0.21 \mathrm{~m}$ and $0.22 \mathrm{~m}$, respectively. Whether general bundle adjustment or GPS-assisted bundle adjustment is used, the self-calibration approach really improves the accuracy of AT. Meanwhile, the general self-calibration bundle adjustment AT uses 28 GCPs and GPS-assisted self-calibration bundle adjustment AT only uses 8 full GCPs. Therefore, 20 GCPs are reduced to achieve cost-saving by GPS-assisted self-calibration bundle adjustment AT.

Additionally, when VBS RTK GPS-assisted self-calibration bundle adjustment without stripwise drift parameters was performed, the RMSE of six check points were $0.51 \mathrm{~m}, 0.29 \mathrm{~m}$ and $4.09 \mathrm{~m}$ in $\mathrm{E}, \mathrm{N}$ and $\mathrm{H}$ coordinate components, respectively. VBS RTK GPS-assisted general bundle adjustment without stripwise drift parameters performed the RMSE of check points with $0.24 \mathrm{~m}$, $0.29 \mathrm{~m}$ and $21.37 \mathrm{~m}$ in $\mathrm{E}, \mathrm{N}$ and $\mathrm{H}$ coordinate components, respectively. However, when GPS-assisted self-calibration bundle adjustment AT was performed using stripwise drift parameters, the RMSEs in $\mathrm{E}, \mathrm{N}$ and $\mathrm{H}$ coordinate components were improved to $0.13 \mathrm{~m}, 0.17 \mathrm{~m}$ and $0.22 \mathrm{~m}$, respectively. The results indicate that stripwise linear drift parameters can overcome GPS antenna-camera offset problems. 


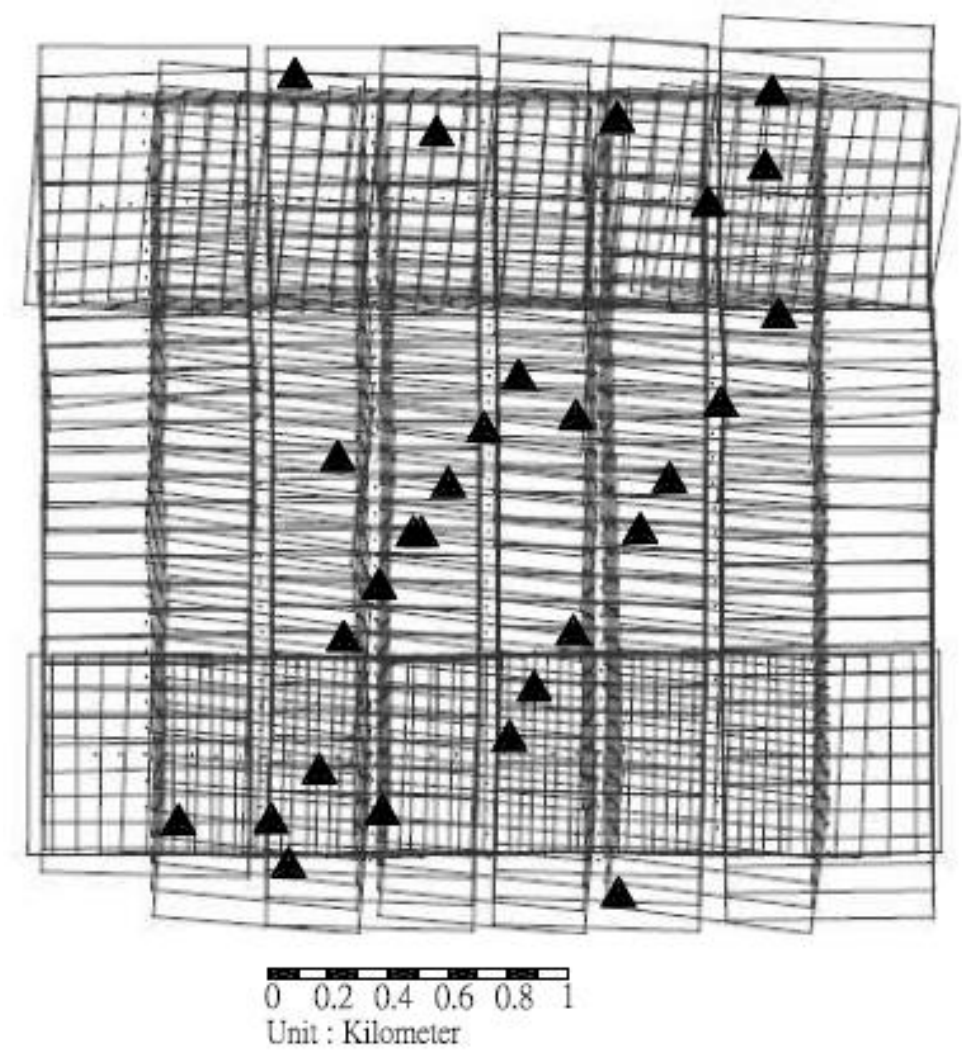

Figure 8: Distribution of 28 full GCPs (triangles) for general bundle adjustment

\subsection{Results of different GCP configurations for VBS RTK GPS-assisted AT}

This test further examined the results of different GCP configurations for VBS RTK GPS-assisted AT of UAS images: (1) two cross strips with 8 full GCPs (Figure 7); (2) two chains of full control points (Figure 9). The photogrammetric software used, the test setup and check points were the same as for the previous test in section 3.2. After AT, approximately 4600 ground tie points remained for two chains of full control points. 

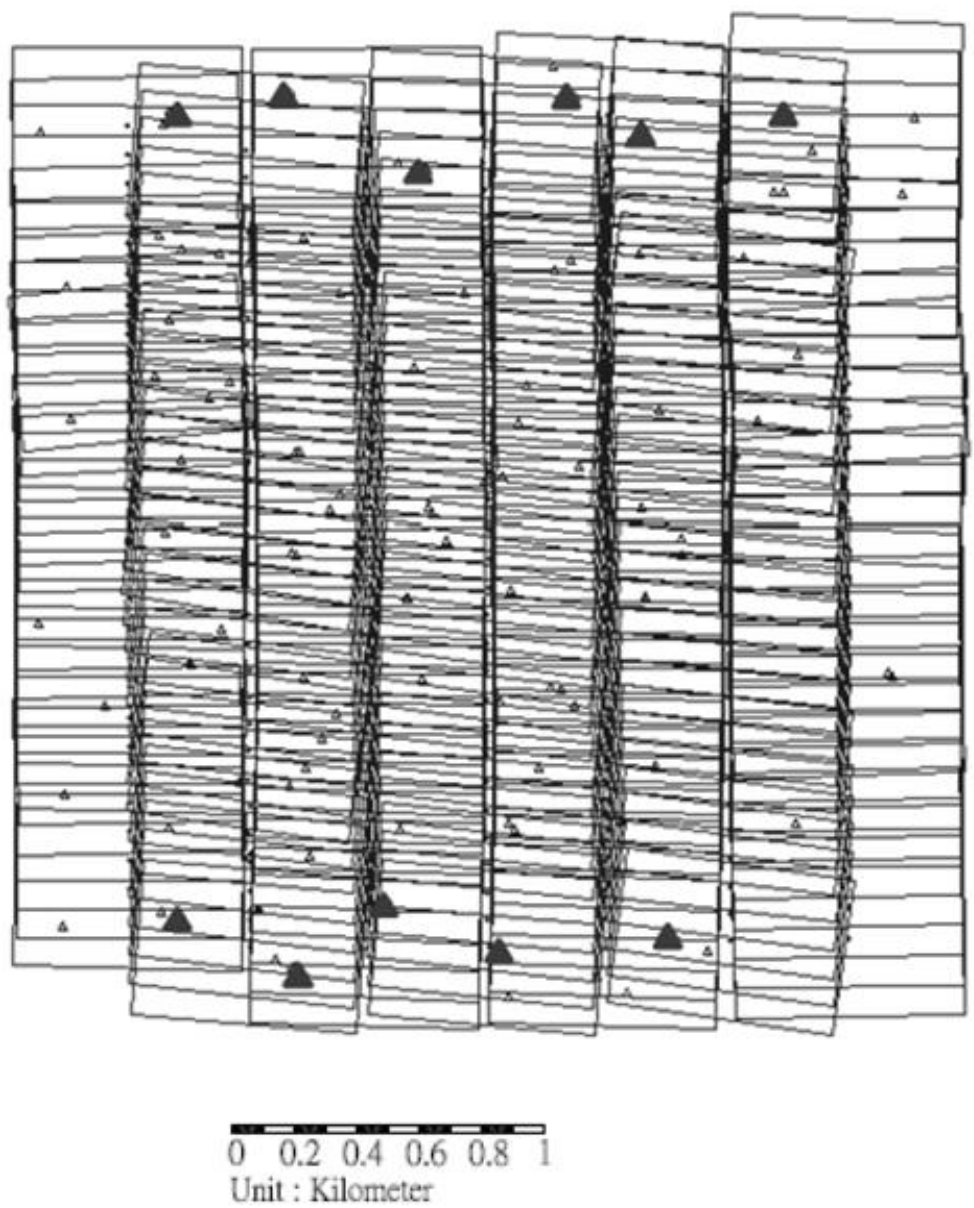

Figure 9: Configuration of GCPs for two chains of full control points

Because of the stronger block geometry achieved by adding two cross strips, the AT accuracy when using two cross strips with 8 full GCPs reaches $0.21 \mathrm{~m}$ in planimetry and $0.28 \mathrm{~m}$ in height (see Table 3 ) and is better than the chains of 11 full GCPs. Adding two cross strips can reduce the demand on the number of GCPs and form a stronger block geometry to significantly improve the results of AT.

Additionally, GCP configuration that uses two chains of full control points requires more time to survey the GCP coordinates. Therefore, two cross strips with 2 full GCPs at each corner of the mapping block is suggested as a GCP configuration, especially if GCP locations are inaccessible.

Table 3: Accuracy of VBS RTK GPS-assisted bundle adjustment AT of UAS images based on two different GCP configurations

\begin{tabular}{l|c|c|c|c}
\hline \multirow{2}{*}{ Configurations of GCPs } & \multicolumn{4}{|c}{ RMSE of 6 check points (unit: meter) } \\
\hline & E & N & E-N & H \\
\hline Two chains of full control points & 0.16 & 0.23 & 0.28 & 0.37 \\
\hline Two cross strips with 8 full GCPs & 0.13 & 0.17 & 0.21 & 0.22 \\
\hline
\end{tabular}




\subsection{Accuracy of stereoscopic viewing}

Because few check points in subsection 3.3 are used to check the accuracy of VBS RTK GPS-assisted AT, this section will further check by stereoscopic viewing. This test used the data of VBS RTK GPS-assisted AT of UAS images in subsection 3.2, i.e. the configuration of GCPs is two cross strips with 8 full GCPs (Figure 7). The check results of stereoscopic viewing are illustrated in Figure 10 and listed in Table 4. The 3-D coordinates of check points are surveyed by the VBS RTK GPS and also measured by stereoscopic viewing using stereo images with $60 \%$ end lap in each strip. The 3-D coordinates of check points surveyed by the VBS RTK GPS are transformed by the same approach used for the transformation of 6 check points for AT. The RMSE of check points from stereoscopic viewing can reach $0.27 \mathrm{~m}$ in planimetry and $0.24 \mathrm{~m}$ in height. In Taiwan, the planimetric accuracy requirement for 1/5000 topographic maps is $1.25 \mathrm{~m}$ and the vertical accuracy requirement for 1/5000 topographic maps is $1 \mathrm{~m}$ in normal terrain [26]. Therefore, the results show that the GPS-assisted self-calibration AT using 266 UAS images in 9 strips, including 2 cross strips and 8 GCPs, yields sufficient accuracy for updating local 1/5000 topographic maps in Taiwan.

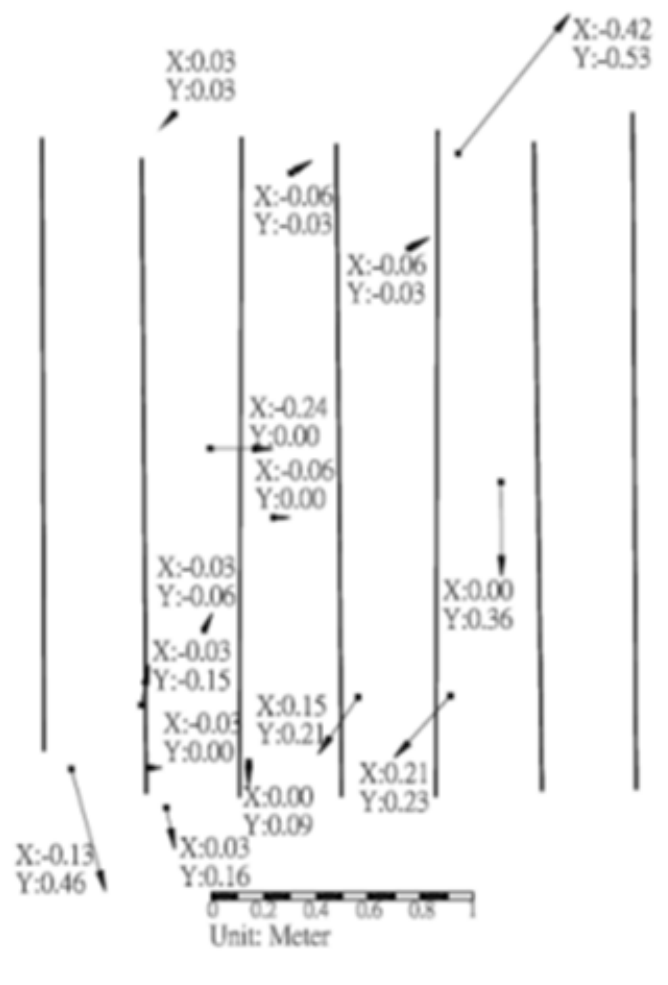

(a) Horizontal check points

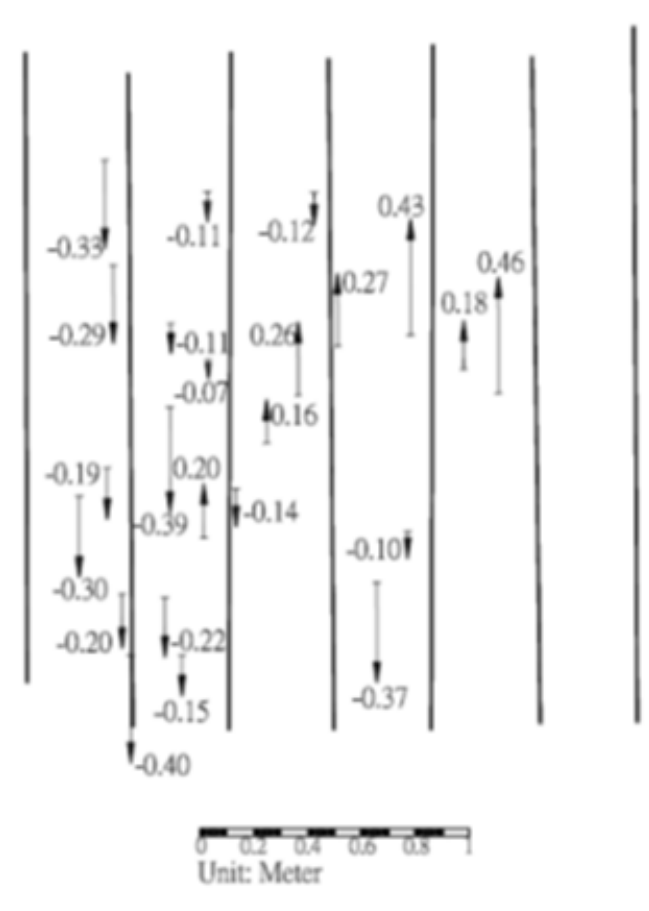

(b) Vertical check points

Figure 10: Distribution and corresponding difference vectors of check points for stereoscopic viewing 
Table 4: The statistics of check results for stereoscopic viewing

\begin{tabular}{l|c|c|c}
\hline & \multicolumn{2}{|c|}{15 horizontal check points } & 23 vertical check points \\
\hline Unit : meter & $\triangle \mathrm{E}$ & $\triangle \mathrm{N}$ & $\triangle \mathrm{H}$ \\
\hline Average & -0.06 & 0.04 & -0.04 \\
\hline Max. & 0.21 & 0.46 & 0.46 \\
\hline Min. & -0.42 & -0.53 & -0.40 \\
\hline RMSE & 0.16 & 0.22 & 0.24 \\
\hline
\end{tabular}

\section{Conclusions}

This study installs a Trimble BD970 GNSS OEM on a fixed-wing UAS for capturing highly accurate GPS data using the VBS RTK GPS technique for GPS-assisted AT, and uses self-calibration bundle adjustment while performing VBS RTK GPS-assisted AT. The test results imply the following conclusions:

(1) This study confirms the feasibility of VBS RTK GPS-assisted self-calibration bundle adjustment for AT of fixed-wing UAS images. The VBS RTK GPS technique only requires a GPS double frequency carrier receiver to be carried on the fixed-wing UAS for capturing highly accurate and precise flying trajectories. Setting up a physical GPS reference base station on site within the mapping area is unnecessary, especially in inaccessible areas such as mountainous areas. The tests prove that this really reduces the ground survey demands placed on GCPs, saving mapping costs and improving mapping efficiency.

(2) This study proves that incomplete camera calibration can be compensated for by self-calibration bundle adjustment AT. The self-calibration approach while performing bundle adjustment AT really improves the accuracy of AT, whether general bundle adjustment or GPS-assisted bundle adjustment is used. Additionally, UAS images collected with a Canon EOS 5D Mark II camera, with a focal length of $24 \mathrm{~mm}$, at a flying height of $550 \mathrm{~m}$ above ground level, using two cross strips with 8 full GCPs produced an AT accuracy of $0.21 \mathrm{~m}$ in planimetry and $0.22 \mathrm{~m}$ in height.

(3) This study also verifies that the problem of antenna-camera offset can be overcome by including linear drift parameters in GPS observation equations on each strip while performing self-calibration bundle adjustment AT for fixed-wing UAS images.

(4) Using two cross strips to strengthen block geometry decreases the number of GCPs. The accuracy of AT for UAS images using two cross strips with 2 full GCPs at each corner is more precise than the accuracy of AT using two chains of full control points at the strip ends and heads. Therefore, using two cross strips with 2 full GCPs at each corner of the mapping area is suggested as an appropriate GCP configuration for VBS RTK GPS-assisted bundle adjustment AT of fixed-wing UAS images. This GCP configuration is efficient, especially for inaccessible mapping areas. The RMSE of check points from stereoscopic viewing can reach $0.27 \mathrm{~m}$ in planimetry and $0.24 \mathrm{~m}$ in height. The test results show that the accuracy of VBS RTK 
GPS-assisted self-calibration bundle adjustment for AT of fixed-wing UAS images can be used for updating local 1/5000 topographic maps in Taiwan.

\section{ACKNOWLEDGEMENTS}

This study was sponsored by grants for the projects "NSC 101-2119-M-004 -001 -". The National Land Surveying and Mapping Center, Taiwan, provided the e-GPS radio instruments. Skyline Dynamics Co. Ltd. and Data Surpass Technology Co. Ltd integrated the VRS GPS receiver hardware. The authors would like to express heartfelt gratitude for all these contributions.

\section{REFERENCES}

Ackermann, F. "Operational Rules and Accuracy Models for GPS Aerial Triangulation." International Archives of Photogrammetry and Remote Sensing 29 (B3) (1992): 691-700.

Ackermann, F. "On the Status and Accuracy Performance of GPS photogrammetry." Proceedings of ASPRS Workshop "Mapping and remote sensing tools for the 21st Century", Washington D.C., USA, 26-29 August, (1994): 80-90.

Bendea, H. F., Chiabrando, F., Tonolo, F. G., Marenchino, D. " Mapping of archaeological areas using a low-cost UAV the Augusta Bagiennorum Test site." Proceedings of XXI International CIPA Symposium, Athens, Greece, 01-06 October, (2007). 6p. (on CD-ROM).

Blankenberg, L. E. "GPS supported aerial triangulation - state of the art." Photogrammetry Journal of Finland 13(1)(1992): 4-16.

Bláha, M., Eisenbeiss, H., Grimm, D. E., Limpach, P. "Direct georeferencing of UAVs." Proceedings of International Conference on Unmanned Aerial Vehicle in Geomatics (UAV-g), Zurich, Switzerland, 14-16 September, (2011): 6p. (on CD-ROM).

Brown, D. C. "The bundle adjustment - progress and prospects." International Archives of Photogrammetry and Remote Sensing 21(Part 3)(1976): 01-33.

Colomina, I. and Molina, P. "Unmanned aerial systems for photogrammetry and remote sensing: A review." ISPRS J. Photogramm. Remote Sens. 92(2014): 79-97.

Chiang, K. W., Tsai, M. L., and Chu, C. H. "The Development of a UAV Borne Direct Georeferenced Photogrammetric Platform for Ground Control Point Free Applications." Sensors 12(7)(2012): 9161-9180.

Clarke, T. A., Fryer, J. G., and Wang, X. "The Principal Point and CCD Cameras." Photogrammetric Record 16(92)(1998): 293-312.

Ebadi, H. "A Comprehensive study on GPS-Assisted Aerial Triangulation." PhD Dissertation, Dept. of Geometrics' Engineering. The University of Calgary, Alberta, Canada.(1997)

Eisenbeiss, H. "A mini Unmanned Aerial Vehicle (UAV): System overview and image acquisition." International Archives of Photogrammetry and Remote Sensing 36 (XXXVI-5/W1)(2004). (on CD-ROM). 
Eisenbeiss, H. "UAV photogrammetry." PhD dissertation, DISS. ETH NO. 18515, Institute of Geodesy and Photogrammetry, ETH Zurich, Switzerland.(2009)

Erdas INC. "LPS Project Manager User’s Guide." Norcross, Georgia. Erdas Inc.(2008)

Fraser, C. S. "Digital camera self-calibration." ISPRS Journal of Photogrammetry \& Remote Sensing, 52(1997): 149-159.

Friess, P. "Kinematic GPS Positioning for Aerial Photogrammetry Empirical Results." Proceedings of International Symposium on Precise Positioning with the Global Positioning System, Ottawa, 3-7 September, (1990): 1169-1184.

Haarbrink, R. B. and Eisenbeiss, H. "Accurate DSM production from unmanned helicopter systems." International Archives of Photogrammetry, Remote Sensing and Spatial Information Sciences 37(B1)(2008): 1259-1264.

Hinsken, L., Miller, S., Tempelmann, U., Uebbing, R., Walker, A. S. "Triangulation of the LH Systems' ADS40 using ORIMA GPS/IMU." International Archives of Photogrammetry, Remote Sensing and Spatial Information Sciences 34(3A)(2002): 156-162.

$\mathrm{Li}, \mathrm{S}$. "The use of Low-altitude unmanned aerial vehicle system in the measurement of large scale topographic maps - Take the 1:2000 mapping of PuWen as an example." Paper presented at 11th South East Asian Survey Congress and 13th International Surveyors' Congress Innovation towards Sustainability, Malaysia, 22-27 June (2011): 8p. (on CD-ROM).

Photometrix PTY LTD. "Users Manual for iWitnessTM and iWitnessPROTM" (2010), pp.98-100.

Trimble. "Product Information." Accessed $\quad$ October 2014. http://www.trimble.com/gnss-inertial/bd970.aspx?dtID=overview.(2014)

Turner, D., Lucieer, A., Wallace, L. " Direct Georeferencing of Ultrahigh-Resolution UAV Imagery." Geoscience and Remote Sensing, IEEE Transactions on, Issue Date: May (2014): 2738 - 2745. http://ieeexplore.iee.. rg/xpls/icp.jsp?arnumber=6553130

Wang, H. L. and Wang, S. C. "Influence of Control Patterns on the Accuracy of the GPS Supported Aerial Triangulation." Journal of Photogrammetry and Remote Sensing 3(2)(1998): 1-15. (in Chinese)

Wolf, P. R. and Dewitt, B. A. eds. Elements of Photogrammetry: with Applications in GIS, " third ed., New York: The McGraw-Hill, .(2000)

Recebido em outubro de 2015.

Aceito em abril de 2016. 